\title{
Effect of Biofilter Operation Parameters on Dimethyl Disulfide Removal : Loading, Time, and Concentration
}

\author{
Bora C. Arpacioglu, Jo-Chun Kim*, Eric R. Allen**, Seoung-Hyun Kim*** \\ HTS Environmental Consulting, Mahatma Gandhi Cad., 107/4 GOP, 06700 Ankara, Turkey \\ ${ }^{*}$ Dept. of Environmental Engineering, Dongshin University, Naju 520-714, Korea \\ ${ }^{*}$ Dept. of Environmental Engineering Sciences, University of Florida, U.S.A. \\ ${ }^{* * *}$ Dept. of Applied Chemistry, Chonnam National University, Gwangju 500-757, Korea
}

(Manuscript received 13 May, 2002 ; accepted 28 June, 2002)

\begin{abstract}
A laboratory-scale dual-column biofilter system was used to study the biofiltration of dimethyl disulfide(DMDS). The biofiltration of DMDS was found to depend on the pollutant loadings rather than the inlet concentrations. It was estimated that the pollutant was only inhibitory to the operation of the biofilters at DMDS concentrations greater than 5500 ppmv. A residence time of 30 seconds $\left(120 \mathrm{~m}^{3} / \mathrm{m}^{2} / \mathrm{h}\right.$ volumetric loading) was determined as appropriate for efficient operation $(>90 \%)$. The maximum elimination capacity for both compost mixtures under the current experimental conditions was found to range from 7.5 to $10 \mathrm{~g}-\mathrm{DMDS} / \mathrm{m}^{3} / \mathrm{h}$. A lower DMDS maximum elimination capacity was exhibited under acidified conditions.
\end{abstract}

Key words : residence time, initial concentration, biofilter, dimethyl disulfide, loading

\section{Introduction}

Dimethyl disulfide (DMDS), a highly odorous chemical substance, is generally found in emissions from wastewater treatment plants and solid waste composting plants. At these facilities, DMDS is released into the atmosphere as a by-product of anaerobic degradation. DMDS is also emitted from pulp and paper manufacturing industries utilizing the Kraft process. In the pulp and paper industries, since DMDS is invariably present in the work atmosphere, it has become a source of interest for industrial hygienists. DMDS is already considered to be highly toxic, yet its toxicology in the human body is still relatively unknown. Therefore, further research is needed to determine the impact of long and short term exposure to DMDS on human health and welfare.

The biological purification of air is not a new

Corresponding author ; Jo-Chun Kim, Dept. of Environ. Eng., Dongshin Univ., Naju, 520-714, Korea

Phone : +82-61-330-3162

E-mail : jckim@white.dongshinu.ac.kr concept. In fact, volatile organic compounds (VOCs) in the atmosphere are continuously absorbed and degraded by plants and soils as part of nature's air cleaning process ${ }^{1)}$. These same biological principles have been widely mimicked in areas of environmental pollution control, such as biological wastewater treatment and bioremediation of contaminated soils. However, acceptance of the use of biological systems in air pollution control has been rather slow. Although there is evidence that biological systems have been used for air pollution control from as early as $1928^{2)}$, no in depth investigations were conducted until the 1970s. Biological gas purification methods have been more widely accepted and used in Europe and Japan than in the United States. In Europe, biofilters are considered as standard odor control techniques $^{3)}$ and their use has recently been expanded to the treatment of dilute VOCs and toxic air pollutant emissions ${ }^{4 \sim 6 \text { ) }}$.

The degradation processes occurring in a biofilter can be described using Fig. 1. Three major processes are assumed to occur in a biofilter : ab- 
sorption, biodegradation, and adsorption. Biofilter beds are filled with support materials, such as soil, compost, peat, etc. Cho ${ }^{\text {y }}$ used a fibrous peat biofilter seeded with aerobically digested night soil sludge to study the removal of organo-sulfur compounds. The peat had an $80 \%$ initial water content and initial $\mathrm{pH}$ of 6.5 , while the bed temperatures were maintained at $18 \pm 3{ }^{\circ} \mathrm{C}$. The inlet DMDS concentration was gradually increased from 5 to 40 ppmv with a constant space velocity of $36 \mathrm{~h}^{-1}$ (equivalent to $100 \mathrm{sec}$ of empty bed residence time). The acclimation period took 6-7 days using a 5 ppmv inlet DMDS concentration. The following order of removability was observed in the peat biofilter : $\mathrm{H}_{2} \mathrm{~S}>\mathrm{MM}$ (methyl mercaptan) $>$ DMDS $>$ DMS(dimethyl sulfide).

Accordingly, the objectives of the current study are to study the effect of residence time on treatment efficiency $(>90 \%)$, determine the typical maximum pollutant elimination capacity of a biofilter compost bed, and investigate the effect of varying inlet DMDS concentrations on the overall biofilter removal efficiency.

\section{Experimental Methods}

\subsection{Laboratory-Scale Biofilter System}

The biofilter system seen in Fig. 2 consisted of an air blower, humidification chamber, syringe pump, and two identical biofilter columns operated in parallel. A half horsepower blower was used to move room air containing pollutant vapor through the biofilter system. Before being introduced to the biofilter columns, the room air was first treated in the humidification chamber. The chamber housed a spray nozzle, which atomized tap water. To increase the amount of contact between the counter-current air flow and the water streams, the humidification chamber was filled with $5 \mathrm{~cm}$-diameter pall rings almost up to the nozzle level. As such, the room air left the humidification chamber with a relative humidity of greater than $95 \%$. The humidified air was transported to the biofilter columns via PVC pipes. Before entering the biofilter columns, liquid DMDS(CAS\#62492-0, $99 \%$ purity, ACROS Chemicals, Pittsburgh,

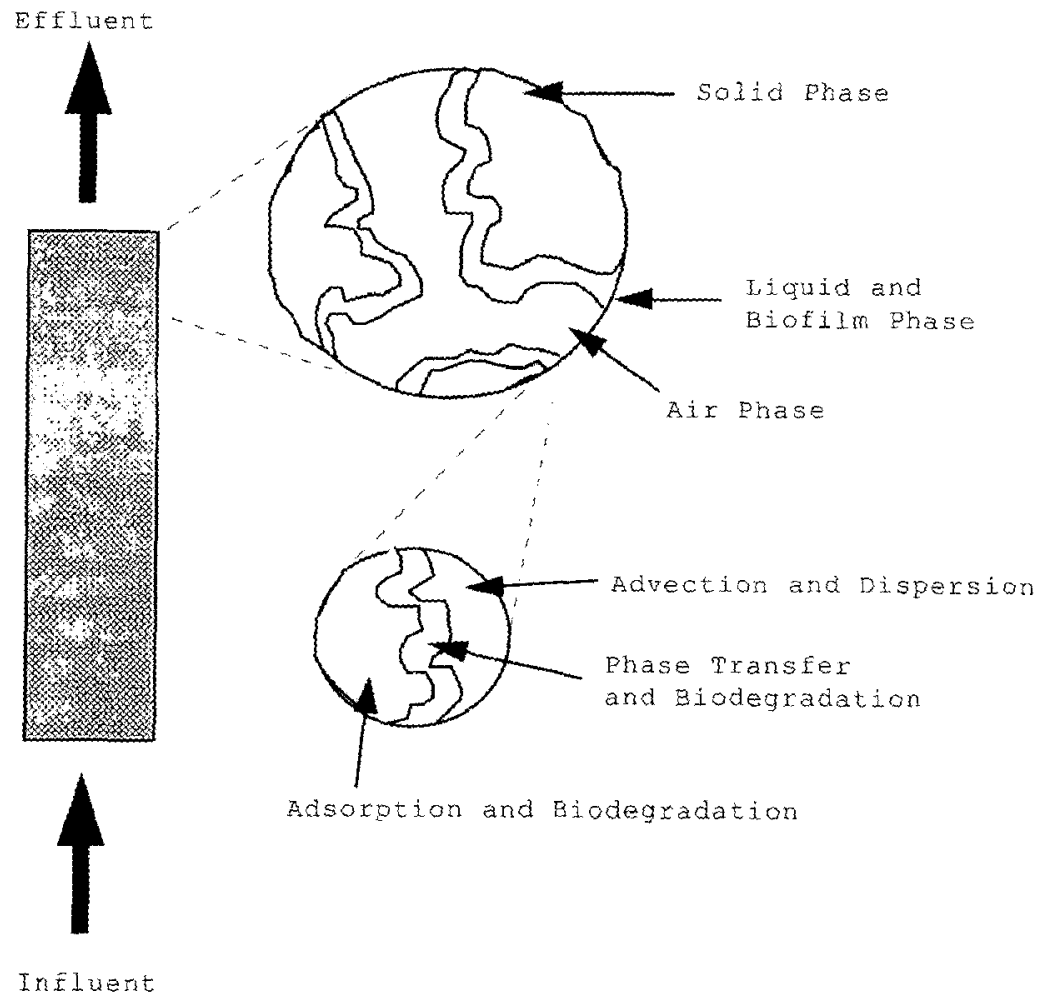

1. Processes Occurring in Biofiltration ${ }^{8)}$. 
PA) was injected into the humid air flow using a syringe pump(Model 355, Sage Instrument, White Plains, NY). The biofilter columns were made of transparent cylindrical Acrylic tubes with a 0.15 $\mathrm{m}$ inner diameter and $1.34 \mathrm{~m}$ length. Access ports were provided at the top and bottom of the columns for the introduction and drainage of liquids. The contaminated air was fed into the compost biofilters at the bottom of the columns. Several ports were located along the vertical packed columns to allow measurements of the gas and compost properties. The columns were packed with compost up to a height of one meter. A perforated Acrylic plate locater above the column inlet was used to support the compost and uniformly distribute the incoming polluted air.

\subsection{Filter Materials}

Two different types of filter material were used
(Atlas Peat and Soil, Inc. Boynton Beach, FL). The composition and physical and chemical characteristics of these materials are given in Table 1. The particle size distributions of the compost materials are provided in Table 2 . The filter material packed in the first biofilter column(\#1) was a compost/pine mulch mixture, whereas the material packed in the second column(\#2) was a compost/ bark nugget mixture. Due to the rather large size of the bark nuggets, the second column biofilter material had a higher percentage of large particles. In fact, more than $50 \%$ of the particles in the second column were larger than $9.5 \mathrm{~mm}$ (equivalent diameter). The larger particle sizes used in the second column may have been advantageous in terms of the pressure drop across the column, yet disadvantageous in terms of providing an adequate active surface area for microbial growth and retention.

\section{Flow Control Devices}

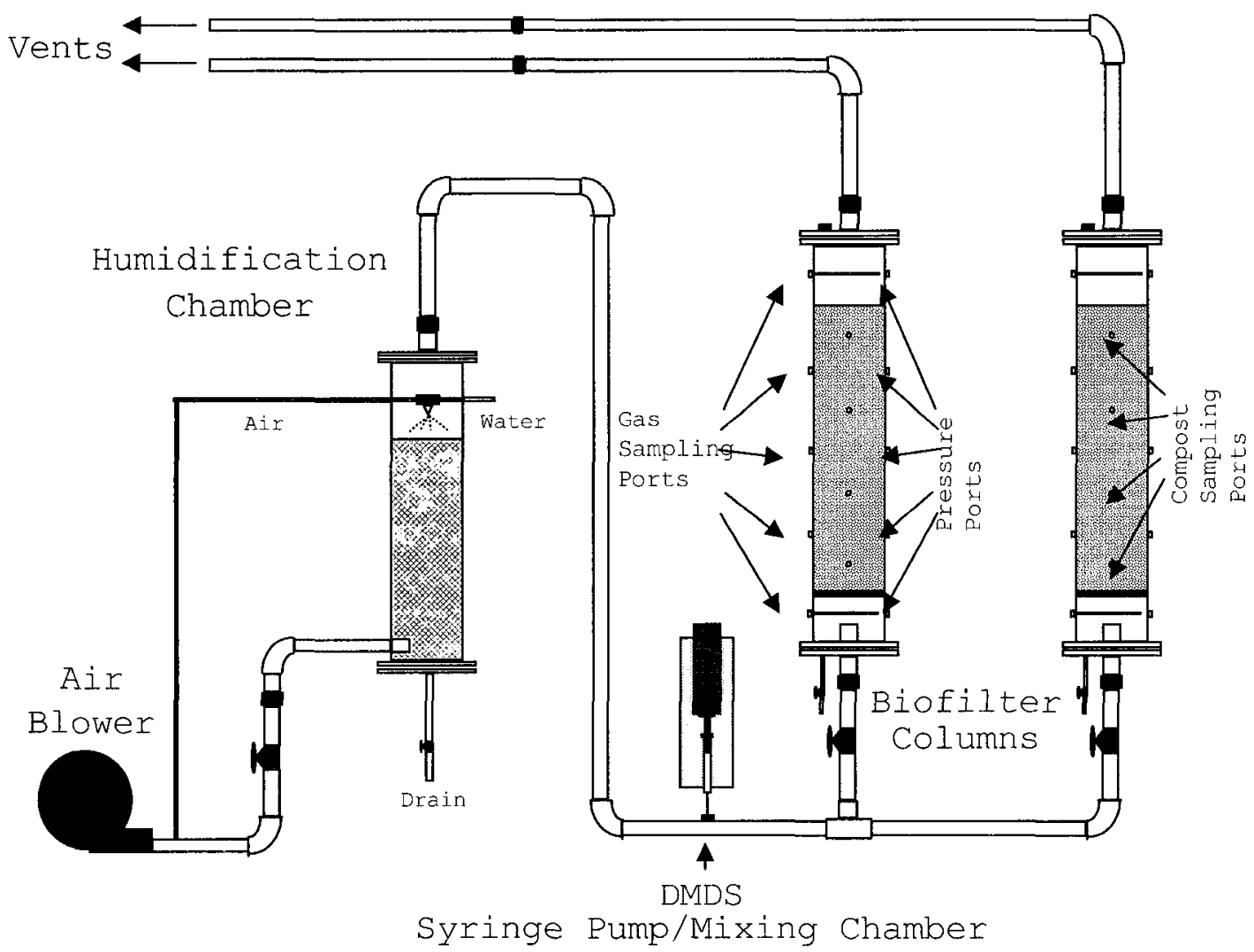

Fig. 2. Dual-Column Biofilter System. 
Table 1. Physical and Chemical Characteristics of Filter Materials

\begin{tabular}{|c|c|c|}
\hline Property & Column-1 & Column-2 \\
\hline Organic Matter Content(wt \%) & 75.1 & 81 \\
\hline Initial $\mathrm{pH}$ & 7.27 & 6.5 \\
\hline Bulk Density $(\mathrm{g} / \mathrm{ml})$ & 0.27 & 0.26 \\
\hline Porosity(vol.\%) & 50.5 & 37.4 \\
\hline Carbon Content(wt.\%) & 32.54 & 39.81 \\
\hline Nitrogen Content(wt.\%) & 0.146 & 0.792 \\
\hline Composition $^{a}$ & $50 \%$ pine mulch ; $50 \%$ compost & $\begin{array}{l}25 \% \text { compost } ; 75 \% \text { deco-pine } \\
\text { bark nuggets }\end{array}$ \\
\hline
\end{tabular}

${ }^{\mathrm{a}}$ Source : Atlas Peat and Soil Co., Boynton Beach, FL.

Table 2. Particle Size Distribution in Filter Materials

\begin{tabular}{c|c|c}
\hline Particle Size Range $^{\mathrm{a}}$ & Column-1 & Column-2 \\
\hline$>9.5 \mathrm{~mm}$ & $7.30 \%$ & $54.60 \%$ \\
\hline $4.8-9.5 \mathrm{~mm}$ & $16.50 \%$ & $9.10 \%$ \\
\hline $2.0-4.8 \mathrm{~mm}$ & $23.60 \%$ & $8.40 \%$ \\
\hline $0.85-2.0 \mathrm{~mm}$ & $17.60 \%$ & $7.60 \%$ \\
\hline $0.43-0.85 \mathrm{~mm}$ & $13.70 \%$ & $6.80 \%$ \\
\hline$<0.43 \mathrm{~mm}$ & $21.30 \%$ & $13.50 \%$ \\
\hline
\end{tabular}

a Equivalent diameter.

The compost mixtures were used without any preliminary size or microbial treatment, however, they were sieved to remove any small particles, so as to decrease the pressure drop. Generally, filter materials are seeded with activated sludge from wastewater treatment plants to introduce the microorganisms necessary for the removal of poorly biodegradable pollutants, such as xenobiotics. A disadvantage of using activated sludge is that it can clog the biofilter and create excessive pressure drops. It is also known that composts are rich in the number and variety of certain yet not all microorganisms necessary for biodegradation. However, the compost mixtures used in the current study were not seeded.

\subsection{Measurement Methods}

\section{2..3.1. Gas Sampling}

The gas samples were extracted from the columns through five gas sampling ports. Each port consisted of a gas collecting assembly made from a $6.35 \mathrm{~mm}$ diameter Teflon tube. The Teflon tubes were modified with fourteen equally spaced ( $1 \mathrm{~mm}$ diameter) holes and packed with glass wool to prevent particles from contaminating the collected gas samples. The Teflon tubes were diametrically extended across the biofilter column to collect a representative gas sample for that specific biofilter bed level.

The gas samples from the ports were slowly expanded into Tedlar bags using the slight positive pressure of the carrier gas in the columns. A staggered sampling method, incorporating a time delay, was used to fill the Tedlar bags at different bed levels. This method allows the same stream of pollutant gas to be sampled at each port, while taking into consideration the time taken for the gas to reach that port.

The samples in the Tedlar bags were analyzed within the same day. The Tedlar bags were completely emptied after the analyses using a vacuum pump and cleaned by sequential flushing with nitrogen gas for reuse. A previous study on sampling reduced sulfur compounds showed that mixtures of reduced sulfur gases in moist air at low ppmv concentrations could be kept in Tedlar bags for up to 7 days with no appreciable losses ${ }^{9}$.

\subsubsection{Gas Sample Analysis}

The gas samples were analyzed for sulfurous compounds using a Gas Chromatograph/Flame Photometric Detector (GC/FPD) (Model 250H, TRACOR Inc., Austin, TX). A sample pump connected to the sample valve effluent line of the GC/FPD was used to draw a gas sample from the Tedlar bag attached to the sample valve inlet line. 
The detector signals from the GC/FPD were then processed using an electronic integrator (Model SP4270, Spectra Physics, San Jose, CA). The GC separation was carried out using a $30^{\prime \prime} \times 1 / 8^{\prime \prime}$ Teflon column packed with Super Q 80/100(Alltech Associates, Inc.). Characteristically, the response of the FPD detectors to the organo-sulfur compounds was non linear. The signal was found to vary approximately linearly with the square of the sulfur concentration. Therefore, the log of the peak area was identified as linearly related to twice the $\log$ of the sulfur concentration. An instrument calibration curve was developed using several dilutions of a standard gas mixture containing $248 \mathrm{ppmv}$ of hydrogen sulfide $\left(\mathrm{H}_{2} \mathrm{~S}\right), 249$ ppmv of methyl mercaptan(MM), 509 ppmv of dimethyl sulfide(DMS), and 248 ppmv of dimethyl disulfide(DMDS) (Specialty Gases, Inc., Ocala, FL). The known dilutions were prepared by injecting known amounts of the standard gas into known volumes of nitrogen gas stored in Tedlar bags. Furthermore, due to analytical difficulties in measuring DMDS, resulting from peak spreading due to the strong retention of the analyte by the column type and conditions employed, the detection limit for the analytical method was only $1.0 \mathrm{ppmv}$ DMDS. Therefore, the concentration range investigated in the current study was limited to values above 10 ppmv.

\section{Results and Discussion}

\subsection{Pollutant Loading}

The pollutant loading(PL) was defined as the amount of pollutant introduced to the biofilters per unit volume of the filter material per unit time, and calculated using the following equation :

$$
P L=\frac{C \cdot Q \cdot K}{V}
$$

where $\mathrm{C}$ is the concentration of DMDS(ppmv), $\mathrm{Q}$ is the gas flow rate $(\mathrm{L} / \mathrm{min}), \mathrm{V}$ is the volume of the filter material $(17.76 \mathrm{~L})$, and $\mathrm{K}$ is the unit conversion factor.

There is a finite limit to the pollutant loading that can be applied to biofilters before the elimination efficiency decreases significantly due to overloading. This limit, called the "Maximum Elimination Capacity"(MEC), is the maximum amount of pollutant that can be degraded by the biofilter without inhibiting normal microbiological functions. The MEC differs for different pollutants, filter materials, and operating conditions. Therefore, the MEC should be assessed for every biofilter application in order to achieve a successful optimal operation.

The values determined for the elimination capacity and MEC for the first(column) compost mixture are shown in Fig. 3. The diagonal solid line represents a theoretically complete $(100 \%)$ treatment. Beyond a critical pollutant loading, the elimination capacity becomes constant, and this pollutant loading is the MEC of the filter material. For the first compost mixture, the MEC was determined to be approximately $10 \mathrm{~g}-\mathrm{DMDS} / \mathrm{h} / \mathrm{m}^{3}$ $\left(6.8 \mathrm{~g}-\mathrm{S} / \mathrm{h} / \mathrm{m}^{3}\right)$. Variations in the $\mathrm{MEC}$ were observed due to changing operating conditions. For example, low elimination capacities were observed with an increased filter bed acidity. The dashed line represents the MEC during acidified conditions (pH near 3). Therefore, the MEC of the first column material was found to range from 7.5 to $10 \mathrm{~g}$ DMDS $/ \mathrm{h} / \mathrm{m}^{3}$. The high elimination capacity of 13.5 g-DMDS $/ \mathrm{h} / \mathrm{m}^{3}$ was also of interest. High elimination capacities were observed during the early stages of the biofilter operation when the adsorptive capacities of the compost filter materials were responsible for the pollutant removal. However, since these high elimination capacities are only temporary in nature, they do not necessarily reflect the true operating MEC of the used filter material for DMDS.

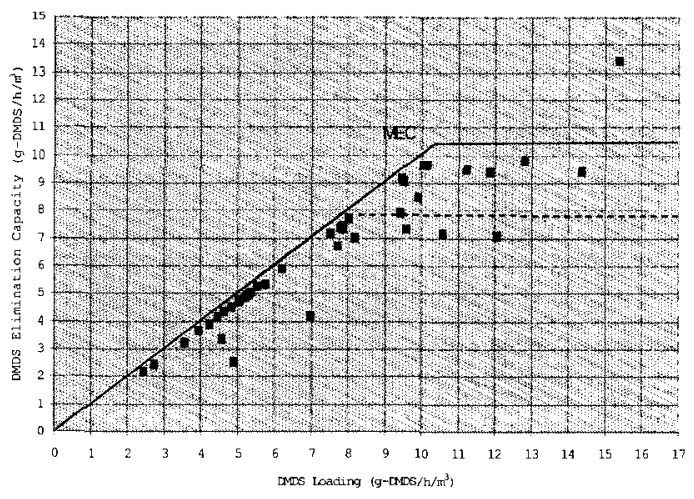

Fig. 3. DMDS Elimination Capacity and Maximum Elimination Capacity for First Column Filter Material. 


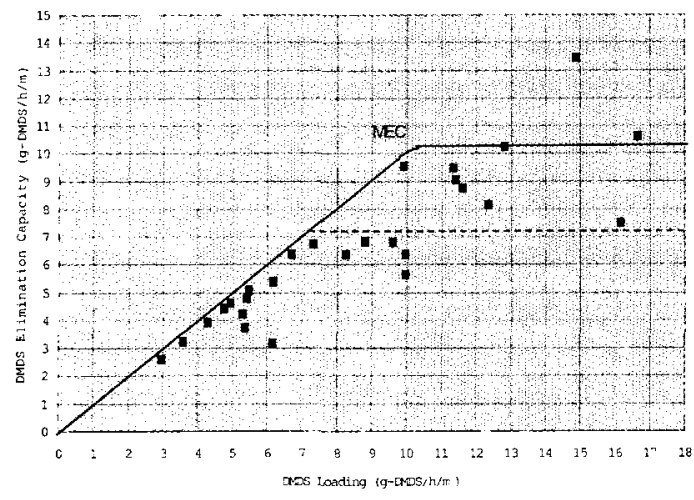

Fig. 4. DMDS Elimination Capacity and Maximum Elimination Capacity for Second Column Filter Material.

The DMDS elimination capacity curve for the second column compost mixture is shown in Fig. 4. The MEC for the second column compost mixture was found to be almost identical to that for the first column compost mixture. The second column compost mixture MEC was only slightly lower than that for the first column mixture. This small difference may have been due to the larger compost particle sizes existing in the second column mixture, resulting in less available surface area for microbial growth.

Park ${ }^{10)}$ used a pilot-scale peat biofilter inoculated with T.thioparus, Strain DW44 to treat $\mathrm{H}_{2} \mathrm{~S}, \mathrm{MM}$, DMS, and DMDS mixtures in emissions from a night soil treatment plant. The MEC value for DMDS observed in that study was 0.004 $\mathrm{g}-\mathrm{S} / \mathrm{kg}$-dry peat/day(equivalent to $0.023 \mathrm{~g}$-S $/ \mathrm{m}^{3}$ -peat $/ \mathrm{h})$. Whereas, the MEC values measured in the current study $\left(5.1 \sim 6.8 \mathrm{~g}-\mathrm{S} / \mathrm{m}^{3} / \mathrm{h}\right)$ were considerably higher. The difference between the results may have been due to the different filter materials employed, operating conditions selected, and/or

Table 3. Effect of Residence Time on Removal Efficiency of DMDS with First Column Filter Material

\begin{tabular}{c|c|c|c|c|c}
\hline $\begin{array}{c}\text { Inlet Conc. } \\
\text { (ppmv) }\end{array}$ & $\begin{array}{c}\text { Outlet Conc. } \\
\text { (ppmv) }\end{array}$ & $\begin{array}{c}\text { Flow Rate } \\
(\mathrm{L} / \mathrm{min})\end{array}$ & $\begin{array}{c}\text { Res. Time } \\
(\mathrm{sec})\end{array}$ & $\begin{array}{c}\text { Pollutant } \\
\text { Loading } \\
\left.(\mathrm{g} \text {-DMDS/h/m })^{3}\right)\end{array}$ & $\begin{array}{c}\text { Removal } \\
\text { Efficiency } \\
(\%)\end{array}$ \\
\hline 15.6 & $<1.0$ & 38.5 & 28 & 7.8 & $>93.6$ \\
\hline 15.4 & $<1.0$ & 28.5 & 37 & 5.7 & $>93.5$ \\
\hline 13.7 & $<1.0$ & 27.2 & 39 & 4.9 & $>92.7$ \\
\hline 18.6 & $<1.0$ & 21.4 & 49 & 5.2 & $>94.6$ \\
\hline 20.7 & $<1.0$ & 19.7 & 54 & 5.3 & $>95.2$ \\
\hline 21.6 & $<1.0$ & 17.8 & 59 & 5 & $>95.4$ \\
\hline 25.1 & $<1.0$ & 16.8 & 63 & 5.5 & $>96.0$ \\
\hline 19 & $<1.0$ & 15.7 & 67 & 3.9 & $>94.7$ \\
\hline
\end{tabular}

Table 4. Effect of Residence Time on Removal Efficiency of DMDS with Second Column Filter Material

\begin{tabular}{c|c|c|c|c|c}
\hline $\begin{array}{c}\text { Inlet Conc. } \\
\text { (ppmv) }\end{array}$ & $\begin{array}{c}\text { Outlet Conc. } \\
\text { (ppmv) }\end{array}$ & $\begin{array}{c}\text { Flow Rate } \\
(\mathrm{L} / \mathrm{min})\end{array}$ & Res. Time (sec) & $\begin{array}{c}\text { Pollutant Loading } \\
\left(\mathrm{g} \text {-DMDS/h/m }{ }^{3}\right)\end{array}$ & $\begin{array}{c}\text { Removal } \\
\text { Efficiency } \\
(\%)\end{array}$ \\
\hline 8.8 & $<1.0$ & 53.1 & 20 & 6.1 & $>88.7$ \\
\hline 9.7 & $<1.0$ & 42.6 & 25 & 5.4 & $>89.6$ \\
\hline 12.8 & $<1.0$ & 36.6 & 29 & 6.1 & $>92.2$ \\
\hline 16.9 & $<1.0$ & 24.6 & 43 & 5.4 & $>94.1$ \\
\hline 18.2 & $<1.0$ & 22.4 & 47 & 5.3 & $>94.5$ \\
\hline 16.7 & $<1.0$ & 21.7 & 49 & 4.7 & $>94.0$ \\
\hline 21.6 & $<1.0$ & 17.4 & 61 & 4.9 & $>95.4$ \\
\hline
\end{tabular}


microorganisms involved. The presence of other interfering sulfurous compounds in the peat biofilter may also have been another reason for the lower MEC values obtained in the earlier study.

\subsection{Effect of Residence Time on Biofilter Removal Efficiency}

The effect of decreasing the overall gas flow rate on the removal efficiency of DMDS was studied by maintaining a relatively constant pollutant loading in the biofilters. Since a decreased residence time produces a lower mass transfer of pollutant from the gas phase to the aqueous liquid phase, a lower residence time was expected to result in a decreased efficiency.

The results when varying the pollutant residence time for the first and second column filter materials are given in Tables 3 and 4, respectively. For the first column filter material, no significant reduction in removal efficiency was observed for residence times as low as 28 seconds. Residence times of less than 28 seconds could not be achieved due to the increased resistance of the filter material to the gas flow. For the second column, filter material residence times down to 20 seconds were tested. A reduction in the removal efficiency was observed for residence times of less than 29 seconds. As such, a minimum residence time of 30 seconds appeared to be adequate to achieve a high removal efficiency $(>90 \%)$.

\subsection{Effect of Inlet Concentration on Biofilter Removal Efficiency}

To observe the effect of a varying inlet DMDS concentration on the overall biofilter removal efficiency, the inlet DMDS concentration was increased at reasonably constant gas flow rates. The results of varying the DMDS inlet concentration on the overall biofilter performance of the first and second column filter materials are presented in Tables 5 and 6 , respectively. At inlet DMDS concentrations near 45 ppmv, the removal efficiency for both column filter materials decreased from about $95 \%$ to approximately $85 \%$. When the inlet DMDS concentration was raised to about $50 \mathrm{ppmv}$, the removal efficiency was reduced to about $70 \%$.

Phatak ${ }^{11)}$ previously reported an inhibitory effect

Table 5. Effect of Inlet DMDS Concentration on Biofilter Removal Efficiency with First Column Compost Mixture

\begin{tabular}{c|c|c|c|c|c|c}
\hline $\begin{array}{c}\text { Inlet } \\
\text { Conc. (ppmv) }\end{array}$ & $\begin{array}{c}\text { Outlet Conc. } \\
(\mathrm{ppmv})\end{array}$ & $\begin{array}{c}\text { Flow } \\
\text { Rate(L/min) }\end{array}$ & $\begin{array}{c}\text { Res. } \\
\text { Time } \\
(\mathrm{sec})\end{array}$ & $\begin{array}{c}\text { Poll. Load Rate } \\
\left(\mathrm{g}-\mathrm{DMDS} / \mathrm{h} / \mathrm{m}^{3}\right)\end{array}$ & $\begin{array}{c}\text { Poll. Elim. } \\
\text { Rate } \\
\left(\mathrm{g}-\mathrm{gMDS} / \mathrm{h} / \mathrm{m}^{3}\right)\end{array}$ & Elim. Eff.(\%) \\
\hline 10.4 & $<1$ & 17.8 & 59 & 2.4 & 2.2 & $>90.4$ \\
\hline 11.6 & $<1$ & 17.8 & 59 & 2.7 & 2.5 & $>91.4$ \\
\hline 13.2 & $<1$ & 20.6 & 52 & 3.5 & 3.3 & $>92.4$ \\
\hline 15 & $<1$ & 21.4 & 49 & 4.2 & 3.9 & $>93.3$ \\
\hline 17.2 & $<1$ & 19.7 & 54 & 4.4 & 4.2 & $>94.2$ \\
\hline 19.8 & $<1$ & 17.8 & 59 & 4.6 & 4.4 & $>94.9$ \\
\hline 20.3 & $<1$ & 19.7 & 54 & 5.2 & 5 & $>95.1$ \\
\hline 21.6 & $<1$ & 17.8 & 59 & 5 & 4.8 & $>95.4$ \\
\hline 24 & $<1$ & 19.7 & 54 & 6.2 & 5.9 & $>95.8$ \\
\hline 29.7 & $<1$ & 20.6 & 52 & 8 & 7.7 & $>96.6$ \\
\hline 43.5 & 6.6 & 19.7 & 54 & 11.2 & 9.5 & 84.9 \\
\hline 46 & 9.4 & 19.7 & 54 & 11.8 & 9.4 & 79.6 \\
\hline 49.6 & 11.2 & 19.7 & 54 & 12.8 & 9.9 & 77.3 \\
\hline 55.7 & 19 & 19.7 & 54 & 14.3 & 9.5 & 66 \\
\hline
\end{tabular}


Table 6. Effect of Inlet DMDS Concentration on Biofilter Removal Efficiency with Second Column Compost Mixture

\begin{tabular}{c|c|c|c|c|c|c}
\hline $\begin{array}{c}\text { Inlet Conc. } \\
(\mathrm{ppmv})\end{array}$ & $\begin{array}{c}\text { Outlet Conc. } \\
(\mathrm{ppmv})\end{array}$ & $\begin{array}{c}\text { Flow Rate } \\
(\mathrm{L} / \mathrm{min})\end{array}$ & $\begin{array}{c}\text { Res. Time } \\
(\mathrm{sec})\end{array}$ & $\begin{array}{c}\text { Poll. Load Rate } \\
\left(\mathrm{g}-\mathrm{DMDS} / \mathrm{h} / \mathrm{m}^{3}\right)\end{array}$ & $\begin{array}{c}\text { Poll. Elim. } \\
\text { Rate } \\
\left(\mathrm{g}-\mathrm{DMDS} / \mathrm{h} / \mathrm{m}^{3}\right)\end{array}$ & Elim. Eff. (\%) \\
\hline 10.4 & $<1$ & 21.7 & 49 & 2.9 & 2.7 & $>90.4$ \\
\hline 12.1 & $<1$ & 22.4 & 47 & 3.6 & 3.3 & $>91.8$ \\
\hline 14.5 & $<1$ & 22.4 & 47 & 4.2 & 4 & $>93.1$ \\
\hline 16.7 & $<1$ & 21.7 & 49 & 4.7 & 4.4 & $>94.0$ \\
\hline 21.6 & $<1$ & 17.4 & 61 & 4.9 & 4.7 & $>95.4$ \\
\hline 27.8 & $<1$ & 18.3 & 58 & 6.7 & 6.4 & $>96.4$ \\
\hline 33.7 & $<1$ & 22.4 & 47 & 9.9 & 9.6 & $>97.0$ \\
\hline 45.1 & 7.2 & 19.2 & 55 & 11.3 & 9.5 & 83.9 \\
\hline 45.4 & 9.1 & 19.2 & 55 & 11.4 & 9.1 & 79.9 \\
\hline 46.1 & 11.1 & 19.2 & 55 & 11.6 & 8.8 & 75.9 \\
\hline 49.1 & 16.5 & 19.2 & 55 & 12.3 & 8.2 & 66.4 \\
\hline
\end{tabular}

on MM degradation at concentrations greater than 20 ppmv and suggested that the biofiltration of MM was more dependent on the MM concentration than on the pollutant loading rate. Therefore, it was interesting to investigate whether DMDS would exhibit a similar biodegradation mechanism. Smith and Kelly ${ }^{12)}$ in their microbiological study of T. thioparus, strain E6, noted that DMDS became inhibitory to microorganisms at an aqueous phase saturation level of $5 \mathrm{mM}$. Knowing that the dimensionless Henry's constant for DMDS is 0.045 mol L ${ }^{-1}$ air mol ${ }^{-1} \mathrm{~L}$ water at $25{ }^{\circ} \mathrm{C}^{13)}$ and assuming that Henry's law constant is applicable at the saturation inhibitory level described previously, the equilibrium concentration for DMDS in air was estimated at 5500 ppmv. Therefore, inlet DMDS concentrations near this value would presumably be inhibitory to microorganisms in the biofilter. However, since the inlet DMDS concentrations used in the current study were much lower than 5500 ppmv, it was concluded that the decrease in the biofilter treatment efficiency with an increase in the DMDS concentration was not due to an inherent inhibitory effect from DMDS, but rather due to overloading caused by an increased pollutant loading rate.

\section{Conclusions}

For the biofilters tested, a residence time of 30 seconds(120 $\mathrm{m}^{3} / \mathrm{m}^{2} / \mathrm{h}$ volumetric loading) was determined as appropriate for efficient operation (>90\%).

The biofiltration of DMDS was found to be dependent on the pollutant loadings rather than the inlet concentrations. It was also estimated that the pollutant would only be inhibitory to the operation of the biofilters at DMDS concentrations greater than 5500 ppmv.

The maximum elimination capacity for both compost mixtures was found to range from 7.5 to $10 \mathrm{~g}$-DMDS $/ \mathrm{m}^{3} / \mathrm{h}$. A lower DMDS maximum elimination capacity was observed under acidified conditions. The first column compost mixture exhibited a slightly higher maximum elimination capacity than the second column mixture, probably due to the presence of a higher fraction of small particles. However, this advantage is partially offset by the economically unacceptable, higher bed pressure drops.

\section{Acknowledgements}

The authors would like to thank International Process Systems (IPS), Inc., Hampton, NH, for their partial support of the current research.

\section{References}

[1] Bohn, H. L., 1992, Consider Biofiltration for 
Decontaminating Gases, Chemical Engineering Progress, April, 34 40.

[2] Eitner, D. and Gethke, H. G., 1987, Design, Construction and Operation of Biofilters for Odor Control in Sewage Treatment.

[3] Ottengraf, S. P. P., Meesters, J. J. P., Van den Oever, A. H. C. and Rozema, H. R., 1986, Biological Elimination of Volatile Xenobiotic Compounds in Biofilters, Bioprocess Engineering, 1, 61 69 .

[4] Azipuru, A., Malhautier, L., Roux, J. C. and Fanlo, L., 2001, Biofiltration of a Mixture of Volatile Organic Emissions, Journal of Air and Waste Manage. Assoc., 51(Dec.), 1662 1670.

[5] Haussard, M., Gaballah, I., Donato, P. de, Barres, O. and Mourey, A., 2001, Removal of Hydrocarbons from Wastewater Using Treated Bark, Journal of Air and Waste Manage. Assoc., 51(Sep.), 1351 1358.

[6] Kim, H.-J., Cho, K.-S., Park, J.-W., Goltz, M. N., Khim, J.-H. and Kim, J. Y., 2001, Sorption and Biodegradation of Vapor-Phase Organic Compounds with Wastewater Sludge and Food Waste Compost, Journal of Air and Waste Manage. Assoc., 51(Aug.), 1237 1244.

[7] Cho, K-S., Hirai, M. and Shoda, M., 1991, Degradation Characteristics of Hydrogen Sulfide, Methanethiol, Dimethyl Sulfide and Dimethyl Disulfide by Thiobacillus thioparus DW44 Isolated from Peat Biofilter, Journal of Fermentation and Bioengineering, 71(6), $384 \sim 389$.

[8] Hodge, D. S. and Devinny, J. S., 1995,
Modeling Removal of Air Contaminants by Biofiltration, Journal of Environmental Engineering, 121(1), 21 32.

[9] NCASI, 1993, A study of the use of tedlar bag sampling for the determination of reduced sulfur gas concentrations in workplace atmospheres, National Council of the Paper Industry for Air and Stream Improvement, Technical Bulletin No. 656.

[10] Park, S-J., Cho, K-S., Hirai, M. and Shoda, M., 1993, Removability of Malodorous Gases from a Night Soil Treatment Plant by a Pilot-Scale Peat Biofilter Inoculated with Thiobacillus thioparus DW44, Journal of Fermentation and Bioengineering, 76( 1), 55 $\sim 59$.

[11] Phatak, S., 1993, Control of Methyl Mercaptan Emissions Using Biofiltration, Master of Engineering Thesis, University of Florida, Gainesville, Fl. Plants, Proceedings of the 80th Annual Meeting of the Air Pollution Control Association, New York, N.Y., Paper No. 87-95A-6.

[12] Smith, N. A. and Kelly, D. P., 1988, Isolation and Physiological Characterization of Autotrophic Sulphur Bacteria Oxidizing Dimethyl Disulphide as Sole Source of Energy, Journal of General Microbiology, 134, 1407 1417.

[13] Przyjazny, A., Janicki, W., Chrzanowski, W. and Staszewski, R., 1983, Headspace Gas Chromatographic Determination of Distribution Coefficients of Selected Organosulfur Compounds and Their Dependence on Some Parameters, Journal of Chromatography, 280, $249 \sim 260$. 